\title{
Working Memory: The What, the Why, and the How
}

Tracy Packiam Alloway and Evan Copello

University of North Florida, Jacksonville, Florida, USA

\begin{abstract}
Working memory, our ability to work with information, plays an important role in learning from kindergarten to the college years. In this article, we review the what, the why, and the how of working memory. First, we explore the relationship between working memory, short-term memory, and long-term memory. We also investigate research on the link between whether environmental factors, such as financial background and mother's educational level, affect working memory. In the next section - the why of working memory - we compare the predictive nature of working memory and IQ in learning outcomes. While IQ typically measures the knowledge acquired by the student, working memory measures what they do with that knowledge. Working memory skills are linked to key learning outcomes, including reading and math. In the final section, we present classroom strategies to support working memory. We also review current research on the efficacy of working memory training.
\end{abstract}

- Keywords: working memory, learning, reading, math, IQ

The aim of this review is to introduce a cognitive skill that has been linked with learning - working memory. We discuss the relationship between working memory and other related cognitive skills, such as short-term memory and long-term memory. Next, we introduce research on the role of working memory in learning and compare it with verbal and nonverbal IQ skills. We conclude by providing classroom strategies that educators can adopt to support working memory. We also discuss research on the efficacy of working memory training.

\section{What is Working Memory? An Introduction}

Working memory is our ability to work with information (Alloway, 2010). This higherlevel skill is involved in directing attention to a task despite distraction or interference (Cowan, 2006; Engle, Tuholski, Laughlin, \& Conway, 1999). Working memory is linked to a range of cognitive activities during the school years, from reasoning tasks to verbal comprehension to mathematical skills (see Cowan \& Alloway, 2008, for a review).

Working memory is distinct from short-term memory, which typically refers to remembering information for a brief period, usually a few seconds (Alloway, Gathercole, \& Pickering, 2006; see McGrew, 2009). We utilise short-term memory when we

Received 3 September 2013; Accepted 1 October 2013

Address for correspondence: Tracy Packiam Alloway, Department of Psychology, University of North Florida, Jacksonville, Florida, USA. Email: t.alloway@unf.edu 
remember someone's name, or a phone number, or a title of a book. Typically, this information will be forgotten if it is not rehearsed. Imagine that you are driving to a new school for a meeting. You lose your way and stop at a store to ask for directions. You may repeat the information to yourself over and over again as you walk back to your car so you do not forget. At this point, you are using your short-term memory to remember the directions. Now you get back inside your car and start driving. As you recite the directions to yourself, you look around and match them to the road names. Is this where you make that right turn? Where do you make that second left? Now you are using your working memory as you are applying or using the information that you were given. It is much the same in the classroom. When you give a student a set of instructions, they use their short-term memory to repeat it to themselves. However, by the time they get back to their desk and have to carry out the first task in the set of instructions, chances are if they have poor working memory, they will have forgotten what to do. The process of repeating the information and then carrying out the individual steps relies on working memory.

Working memory is also distinct from long-term memory, though there is close relationship between them, much like a two-way street. Long-term memory refers to memories from our childhood, but it also refers to the knowledge that we have accumulated over the years, such as facts about a country, mathematical knowledge, and grammar rules. One goal of working memory is to transfer new information to our long-term memory. For example, if we are planning a trip to a country that we have not visited before, we use our working memory to retain and transfer the knowledge we learn about that country to our long-term memory. In turn, we can draw on long-term memory to form associations between a familiar place and the new country we are about to visit.

\section{Working Memory and the Environment}

Given that working memory is linked to long-term knowledge stores, one issue is the extent to which working memory is influenced by environmental factors that contribute to knowledge acquisition. Of particular interest is the impact of socioeconomic status (SES) as this has long been linked with school success, and the income-achievement gap is evident in kindergarten and accelerates over time (Kaplan et al., 2001). However, with respect to working memory, SES does not appear to have a significant impact on performance. For example, children from low-SES areas in South America did not differ significantly from their middle-SES peers in some working memory tests, although their vocabulary scores, reflecting knowledge-based skills, were considerably worse (Engel, Heloisa Dos Santos, \& Gathercole, 2008). Dutch studies investigating differences between immigrant children that typically reside in low-income areas (indexed by parental educational), and comparatively wealthier native language speakers found that the former group performed at the same level as their native language peers in working memory tests when tested in their own language (Messer, Leseman, Mayo, \& Boom, 2010; also Leseman, Scheele, Mayo, \& Messer, 2007). Typically, there are multiple indices of SES, such as family income and parental education, though studies of only parental education have reported that SES is not linked to working memory performance (Alloway, Gathercole, Willis, \& Adams, 2004; Messer et al., 2010).

However, some researchers have reported a differentiation of working memory performance as a function of SES levels (Noble, McCandliss, \& Farah, 2007; Noble, 
Norman, \& Farah, 2005). There are two explanations for this disparity in the impact of SES on working memory. The first explanation is sample age, as the chronic stress hypothesis suggests that the prolonged exposure to poverty can result in chronic stress, which in turn leads to reductions in working memory performance (Evans \& Schamberg, 2009). According to this hypothesis, SES would have a greater impact on older children compared to younger ones. This pattern appears to hold true as studies with older samples (10-13 years) found differences in spatial memory (keeping a location in mind) and the $n$-back task (Farah et al., 2006). Evans and Schamberg (2009) also reported working memory deficits in their 17-year-olds, as a function of SES. In contrast, studies with young populations reported that working memory was relatively unaffected by SES levels (e.g., Alloway et al., 2004, with British 4- to 5-year-olds; Engel et al., 2008, with Brazilian 6- to 7-year-olds; Messer et al., 2010, with Dutch 4-year-olds). One exception is a study with first-graders in New York City (Noble et al., 2007; Noble et al., 2005), which will be discussed further in the following paragraph.

The tasks used to measure working memory can also affect findings as some studies use tasks that are similar to short-term memory ones (e.g., Noble et al., 2007). Such tasks do not involve any processing of information, which is reflective of working memory, and may rely more on knowledge structures (Alloway et al., 2006). As a result, performance may be more sensitive to SES variations, which may account for Noble et al.'s findings. Indeed, Farah et al. (2006) argued that SES has differential effects on tasks associated with different neurocognitive systems. They reported the greatest effects in the left perisylvian/language system (measured by tests of receptive vocabulary and grammar), but no effect on the parietal lobe/spatial cognition (measured by mental rotation tasks).

\section{Why is Working Memory Important?}

Working memory is critical for a variety of activities at school, from complex subjects such as reading comprehension, mental arithmetic, and word problems to simple tasks like copying from the board and navigating around school. It is also important from kindergarten (Alloway et al., 2005) to the tertiary level (Alloway \& Gregory, 2012).

\section{Working Memory and Reading}

A key foundational skill in reading success is known as phonological awareness, where the child must dissect a word into its parts, such as rhyming words or words with the same initial sounds, and the ability to name pictures rapidly. A 5-year longitudinal study of several hundred children who were tracked from kindergarten through fourth grade confirmed that phonological awareness skills predicted reading proficiency (Wagner et al., 1997).

Working memory is also highly predictive of reading success. In typically developing children, scores on working memory tasks predict reading achievement independently of measures of phonological awareness (Swanson \& Beebe-Frankenberger, 2004). One explanation for why working memory is so critical for reading is that we use our 'Postit Note' (or working memory capacity) to keep all the relevant speech sounds in mind, match them up with the corresponding letters, and the combine them to read the words. Indeed, children with reading difficulties have been found to have a limited 
capacity for processing and storing information (De Jong, 1998), and often show significant and marked decrements on working memory tasks (Siegel \& Ryan, 1989).

Working Memory and Mathematics

Working memory is also linked to math outcomes: low working memory scores are closely related to poor performance on arithmetic word problems (Swanson \& SachseLee, 2001; also Alloway \& Passolunghi, 2011) and poor computational skills (Bull \& Scerif, 2000; Geary, Hoard, \& Hamson, 1999).

Although there is also a close relationship between mathematical skills and working memory, this is mediated by the age of the child, as well as the task. Verbal working memory plays a strong role in math skills in 7-year-olds (Bull \& Scerif, 2001) and is also a reliable indicator of mathematical difficulties in the first year of formal schooling (Gersten, Jordan, \& Flojo, 2005). However, once children reach adolescence, working memory is no longer significantly linked to mathematical skills (Reuhkala, 2001). One explanation for this change is that verbal working memory plays a crucial role for basic arithmetic (both to learn arithmetic facts and to retain relevant data such as carried digits) but that as children get older other factors, such as number knowledge and strategies, play a greater role (Thevenot \& Oakhill, 2005). Low working memory scores are related to poor computational skills (Bull \& Scerif, 2001; Geary, Hoard, \& Hamson, 1999) and poor performance on arithmetic word problems (Swanson \& Sachse-Lee, 2001).

Visuo-spatial memory is also closely linked with mathematical skills. It has been suggested that visuo-spatial memory functions as a mental blackboard, supporting number representation, such as place value and alignment in columns, in counting and arithmetic (D'Amico \& Guarnera, 2005; Geary, 1990; McLean \& Hitch, 1999). Specific associations have been found between visuo-spatial memory and encoding in problems presented visually (Logie et al., 1994), and in multi-digit operations (Heathcote, 1994). Visuo-spatial memory skills also uniquely predict performance in nonverbal problems, such as sums presented with blocks, in pre-school children (Rasmussen \& Bisanz, 2005).

\section{Working Memory Versus IQ $^{1}$}

Many studies have demonstrated that both IQ and working memory are related to learning. In the research lab, we investigated which is more important. This issue is important so that educators can target and support the cognitive skills that underpin success in learning. In order to investigate how well IQ and working memory would predict reading, writing, and math skills, a group of 5-year-olds $(n=194)$ was tested as they started kindergarten and tracked over a 6-year period. The findings at the first time point (age 5) indicated that working memory was a significant predictor of reading, writing and math. Children with high working memory did well in reading, writing, and math; while those with low working memory struggled in these tasks (Alloway et al., 2005).

The children were tested again when they were 11 years old in order to explore the best predictors of learning outcomes over time - working memory or Verbal IQ/Performance IQ (VIQ/PIQ). They were also tested on standardised tests of language and math. The results indicated that a student's working memory ability at 5 years of age was a significant predictor of language and math scores 6 years later (Alloway \& Alloway, 2010). This finding is important as it indicates that while IQ is still viewed 
as a benchmark of success, other skills, such as working memory, may provide more useful information on a student's potential to learn.

Numerous studies have demonstrated that working memory is a distinct skill from IQ (Cain, Oakhill, \& Bryant, 2004; Siegel, 1988), and uniquely predicts learning outcomes. For example, working memory skills predict a child's performance in language and math, even after a child's IQ scores have been statistically accounted (Gathercole, Alloway, Willis \& Adams, 2006; Nation, Adams, Bowyer-Crane, \& Snowling, 1999; Stothard \& Hulme, 1992; for a review see Swanson \& Saez, 2003). The importance of working memory in learning is not just limited to children. This same pattern is evidenced at the university level as well: working memory is a better predictor of grades than entrance exams like SAT scores (Engle et al., 1999).

Why is working memory a better predictor of learning than IQ? Working memory tests measure something different from IQ tests: working memory is an indicator of our potential to learn. A common working memory test is to remember a sequence of numbers in the reverse order that it was presented to you. If students struggle in this test, it is not because they do not know how to count, or understand number magnitude. It doesn't even matter whether they can recognise the numbers. If they struggle in this working memory test, it is often because their 'Post-it Note' (or working memory capacity) isn't big enough to remember three or four numbers. Working memory is an accurate predictor of learning from kindergarten to college because it measures students' ability to learn, rather than what they have learned.

In contrast, other measurements like school tests and IQ tests measure knowledge that they have already learned. If students do well on one of these tests, it is because they know the information they are tested on. Likewise, many aspects of IQ tests also measure the knowledge that we have built up. A commonly used measure of IQ is a vocabulary test. If students know the definition of a word like 'bicycle' or 'police', then they will likely get a high IQ score. However, if they do not know the definitions of these words or perhaps do not articulate them well, this will be reflected in a low IQ score. In this way, IQ tests are very different from working memory tests because they measure how much students know and well they can articulate this knowledge.

One research project involved two different schools: one was in an urban, developed area, while the other was in an underprivileged neighborhood (Alloway, Alloway, \& Wootan, 2013). As part of the project, students' IQ was tested using a vocabulary test. One of the vocabulary words - police - drew very different responses. Students from the urban school provided definitions relating to safety or uniforms, which corresponded to the examples in the manual. However, those from the underprivileged neighborhood responded with statements such as 'I don't like police' or 'They are bad because they took my dad away'. Although both responses were drawn directly from the children's experiences, only one type of answer matched the IQ manual's definitions. This example illustrates how performance on IQ tests is strongly driven by a child's background and experiences.

\section{HOW Can We Diagnose and Support Working Memory?}

Testing Working Memory

How can you detect working memory problems in a student? If we fall and break a leg, a cast is clearly visible. Yet working memory problems are often hidden from family, friends, and even teachers. In interviews with classroom teachers, we found that 
working memory failure in a student is often overlooked (Alloway, Doherty-Sneddon, \& Forbes, 2012). Instead, the student is often thought of as lazy or unmotivated. Comments such as 'You are not trying hard enough' or 'Stop playing around and just focus' are often directed towards the student with working memory problems.

\section{Case Study}

Jenny, 14 years, had difficulty staying on task and always seemed to be two steps behind in her class assignments. In Science class, she had to label and remember the planets in the solar system. The next step was to apply this information to an in-class project. However, when the researcher (EC) walked over to her desk, he noticed that she was still working on the labels - an activity that should have been completed the previous day.

She displayed similar behaviour in her English class. When her teacher asked her to express her thoughts on an essay that was just read to the class, she answered with remarks pertaining to the essay read the day before. When the teacher reprimanded her for not paying attention, she seemed confused and did not understand what she had done. Her mind always seemed to be on the previous day's work, and her performance in classes suffered as a result. She was in a vicious cycle of being a day behind because she could not maintain focus long enough to complete any assignments. Not only were her grades suffering, but also she was frequently frustrated due to the constant reprimands and poor performance she dealt with on a regular basis.

Jenny is an example of classroom behaviour that is characteristic of a student with working memory difficulties. It is not uncommon for working memory difficulties to be regarded as attention problems. Students can lack direction, appear unmotivated, or simply disinterested in the activity. The Working Memory Rating Scale (WMRS) is a behavioural rating scale developed for educators to help them easily identify students with working memory deficits. It consists of 20 descriptions of behaviours characteristic of children with working memory deficits. Teachers rate how typical each behavior was of a particular child, using a 4-point scale ranging from (0) not typical at all to (1) occasionally to (2) fairly typical to (3) very typical.

A starting point in developing the items in the WMRS was an observational study of students with low working memory but typical scores in IQ tests. Compared with classmates with average working memory, the low memory students frequently forgot instructions, struggled to cope with tasks involving simultaneous processing and storage, and lost track of their place in complex tasks. The most common consequence of these failures was that the students abandoned the activity without completing it.

As the WMRS focuses solely on working memory-related problems in a single scale, it does not require any training in psychometric assessment prior to use. It is valuable not only as a diagnostic screening tool for identifying children at risk of poor working memory, but also in illustrating both the classroom situations in which working memory failures frequently arise, and the profile of difficulties typically faced by students with working memory difficulties. The scores are normed for each age group, which means that they are representative of typical classroom behavior for each age group. One item in the WMRS is 'needs regular reminders of each step in the written task'. The classroom teacher has to rate how typical this behaviour is of the student and compare their score to the manual. A 5-year-old would need more reminders than a 10-year-old, which is reflected in the scoring of the WMRS. The 
scoring is color-coded to make it easy to interpret. For example, a score in the Green range indicates that it is unlikely that the student has a working memory impairment. If a student's score falls in the Yellow range, it is possible that they have a working memory impairment and further assessment is recommended. Scores in the red range indicate the presence of a working memory and targeted support is recommended.

The WMRS has been validated against other behaviour rating scales, such as the Conners Teacher Rating Scale and the BRIEF (Alloway, Elliott, \& Place, 2010). The WMRS measures behaviour that is different from that represented in these other rating scales, and thus reliably identifies students with poor working memory. The WMRS has also been compared to cognitive tests of working memory, IQ, and academic attainment. The majority of students considered by their teachers to have problematic behaviours (i.e., typical of poor working memory) are more likely to have low working memory scores and achieve low grades (Alloway, Gathercole, \& Elliott, 2010).

It is important to know that students who display poor working memory behavior will not necessarily have low IQ scores. Many of them can have average IQ scores. Yet, it is working memory overload that leads to all the behaviours we have discussed and their loss of focus in the task can appear to be inattentive and distracted to others. The WMRS enables teachers to use their knowledge of the student to produce an indicator of how likely it is that the child has a working memory problem. Thus, it provides a valuable first step in detecting possible working memory failures.

\section{Cognitive Tests of Working Memory}

Case Study

Mary, 14 years, struggled in writing assignments. If a writing assignment extended
over several days, she had a difficult time remembering her train of thought from
her previous writing session. She needed hands-on support from her teacher and
asked questions frequently to guide her activities. When she was asked to read her
writing out aloud, her reading was uncertain and sounded similar to reading an
unfamiliar text. She would skip lines and mingle sentences together from different
parts of the paper. She required extra attention and guidance in order to complete
her assignments.

Educators are growing increasingly aware that students like Mary have working memory difficulties that can impact their learning. Test publishers are also recognising the importance of working memory in education. Many standardised IQ test batteries, such as the Wechsler's Intelligence Scale, Stanford-Binet, and Woodcock Johnson, all include working memory tests as part of their assessment. However, these batteries are limited as they do not include visuo-spatial working memory tests and so do not provide a working memory profile of strengths and difficulties that can inform individualised education plans.

In order to address this need, the Alloway Working Memory Assessment (AWMA; Alloway, 2007) Alloway Working Memory Assessment - 2 (Alloway, 2012B) were developed. This standardised battery is fully automated and provides assessments of verbal and visuo-spatial working memory, making it convenient for teachers and educational professionals alike, to screen individuals for significant working memory problems. Working memory tasks involve both remembering and processing information, while short-term memory is assessed using tasks that involve only remembering information. The AWMA uses a variety of stimuli. For example, tests of verbal working 
memory consist of letters and numbers, and the visual-spatial working memory tests include dot locations and three-dimensional arrays of blocks. Multiple methods of assessing the same underlying aspect of working memory allow the test administrator to distinguish whether a student has a working memory deficit or as difficulty in processing a particular type of stimulus.

The AWMA uses a span procedure, which makes it particularly suitable when testing both children and adults. The number of items to be remembered is increased over successive trials until the individual begins to struggle. Memory span (capacity) is the maximum amount of information that an individual can remember accurately. For example, in the backward digit recall test (verbal working memory), an individual remembers numbers in backwards order. If they are unable to remember five numbers, then the task ends and the individual's memory capacity is four items.

\section{Benefits}

1. The AWMA is quick: It takes 10 minutes. The Screener version of the AWMA can be used to screen students with suspected working memory difficulties. It consists of the following two tests: Processing Letter Recall and Mr X. For a more detailed memory profile of the student, the AWMA also includes a Short Form, which includes tests of verbal short-term memory and visual-spatial short-term memory in addition to the working memory ones in the Screener. The administration time is approximately 20 minutes for all individuals. A Long Form with multiple assessments of each memory component is also included in the AWMA. It takes approximately 30 minutes to administer. One reason that the AWMA is easy for teachers to use is that the program automatically generates a report with standard scores and percentiles that is easy to interpret once the test is completed.

2. The AWMA has good reliability. Test reliability refers to the consistency with which a test can accurately measure what it aims to do. If an individual's performance remains consistent over repeated trials, it is considered to be reliable. Thousands of students have been tested and then re-tested on the AWMA 6 weeks and 1 year apart. The test-retest scores for the AWMA are high, indicating that the AWMA captures the stability of working memory over time (Alloway, Gathercole, Kirkwood, \& Elliott, 2008).

3. The AWMA has good validity. Test validity refers to whether a test accurately measures the skills it is designed to measure. In order to establish test validity, I took a group of students with poor working memory as identified by the AWMA and compared their scores in the Wechsler Working Memory Index (WMI; Alloway, Gathercole, Kirkwood, \& Elliott, 2009). The majority of students who achieved low scores on the AWMA also scored poorly on the Wechsler WMI. This pattern establishes that AWMA provides a valid measure of working memory.

The AWMA is effective in identifying students at risk. In a study of 3,000 students, the majority of students with poor working memory also scored poorly on a standardised attainment test and vocabulary (Alloway et al., 2009). Scores on the AWMA can also identify those who need extra support in the classroom, as well as those 
who take longer to process information and so would benefit from extra time during assessments.

\section{Supporting Working Memory Through Strategies}

Classroom teachers can make small tweaks in the daily routine of the student to support their learning.

1. Detect working memory failures. Is the student struggling to keep up with their peers? Are they beginning to disengage from the activity? Are they acting out in frustration? Once you have identified these signs in a student, you can follow the next two recommendations.

2. Break down information. If an activity exceeds the working memory capacity of a student, they will be unable to complete the task.

3. Build long-term knowledge. This process can foster automaticity of knowledge in the student, which can ease the likelihood of working memory overload.

The following case studies illustrate how these steps can be implemented in a classroom setting.

\section{Case Study}

Jimmy, 10 years, had difficulty issues recalling information, as well as completing simple tasks. His writing skills were poor and his reading comprehension was also much lower than the rest of his classmates.

1. Detecting working memory failures. When the researcher (EC) reviewed his lesson plans, he realised that the time that the class worked on certain assignments changed every day. Jimmy found it difficult to work within this varying schedule and was frequently frustrated. In order to support his learning and keep him apace with his classmates, the researcher started by developing a structured schedule for him. For example, every day at the same time he would complete writing activities, regardless of what the rest of the class was doing. Now that his day was structured, he knew exactly what to anticipate and was mentally ready to tackle his next assignment. His behaviour improved as a result.

2. Break down information. During writing assignments, the researcher would break down complex sentences and have Jimmy write one sentence at a time. After each paragraph, the researcher would read it aloud to Jimmy and then ask him to read it. Eventually he was able to write multiple sentences at a time without prompting, and read the paragraph aloud to the researcher before it was read to him.

3. Build long-term knowledge. Each day, the researcher would review the multisyllable words with Jimmy and reinforce meaning. The next day the researcher would ask him what the word meant. The word 'because' perplexed him at first. One day, they used it in a sentence and read it together, and the researcher explained the meaning of the word, as well as the proper usage. The next day during Jimmy's writing assignment, he had to use the word in one of his sentences. He was able to use the word effectively and continued to better its usage throughout the week. 
Developing a schedule, breaking down the writing assignments, and explaining the meaning of words allowed him to catch up with his classmates in writing and reading assignments.

\section{Case Study}

Janine, 11 years, was having difficulty with manipulating three and four digit numbers.

1. Detecting working memory failures. When the researcher (EC) first assessed her ability, he realised she was proficient with two-digit multiplication, but the borrowing system with three digits confused her. The same issue was evident with her long division.

2. Break down information. The researcher began with asking her to add multidigit numbers together (e.g., $345+678$ ). After successfully completing this task, he asked her to multiply the same numbers together, guiding her through each step along the way and talking about each step. They spent a week doing this together. Her homework assignments had to be completed in a quiet room away from televisions and radios. If she had any difficulties with the math problems, she was instructed to make a note next to the problem and move onto the next one (to avoid her adopting incorrect techniques). The following day they would review her notes and the next homework assignment contained problems that mimicked the ones she had difficulties with. Eventually she was able to confidently perform complex multiplication with ease.

The next challenge was long division. The multiplication sessions began by going over simple division (e.g., 16/4) and going through them step by step. Janine began by only dividing numbers that were even, and eventually integrated simple numbers with decimals. After integrating decimals, she was moved on to even-number long division (e.g., 100/5). The researcher went through these step by step with her until she could do them with ease. She began to remember the steps in the process, as well as the rules of long division. Once she demonstrated signs of proficiency in these problems, she moved onto three- and four-digit long division. After she showed progress with those, she was given integrated decimal division. Her homework assignments mirrored what she learned in class, as well as added a few complex problems.

3. Build long-term knowledge. After a month of learning complex multiplication and division, Janine was given an assessment. The assessment required her to write down each step of the process for the multiplication and division problems. She was then given math problems that steadily progressed in difficulty. She improved greatly from the start of our sessions. By starting at the basic level of each process she was able to build the necessary rules to do more complex problems later on. She eventually was teaching herself with ease. By building proper study habits and learning habits she was able to learn and recall information that used to difficult for her.

\section{Training}

Recently, there have been several reviews on the efficacy of working memory training (Buschkuehl, Jaeggi, \& Jonides, 2012; Jaeggi, Buschkuehl, Jonides, \& Shah, 2011; Morrison \& Chein, 2011, for reviews). While there are both positive findings, as well as null results, the key is the working memory program — we cannot apply a blanket 
statement that all training works (or does not work). Based on research, here are three key things to look for when evaluating the research findings:

1. Control group. A control group offers a comparison to make sure that the training program is not just working because the child is doing something different. Some studies just use a control group who do not do anything. While this is a good start, an ideal control group is a group of people who are doing something different from the training program (such as reading or playing a different computer game). We recently published findings on a working memory training program, Jungle Memory, that included a control group that received additional educational support (Alloway, 2012a). The findings indicated that the training group performed significantly better than the control group in standardised tests of IQ and working memory after an 8 -week period. Jaeggi et al. (2011) also reported improvements in a non-verbal IQ after a working memory training task ( $n$-back task) in young adults.

2. Transfer effects. This refers to whether the program improves anything other than getting better at the game itself. Practising one thing will naturally make you better at it. This is known as a practice effect. But can the benefits of a brain training program transfer to real world activities? In other words, can you get better at something other than the training game? In clinical trials, Jungle Memory showed transfer effects the students showed improvements not just in working memory, but in IQ, and more importantly, in grades as well (Alloway, 2012a).

3. Maintenance. How long do the results last? It is important to consider whether the training benefits will last beyond the training period. In a study of almost 100 students, we found that the benefits of Jungle Memory training persisted when students were tested 8 months later (Alloway, Bibile, \& Lau, 2013).

In summary, working memory is a foundational skill for learning. It measures our ability to work with information and is linked to learning from kindergarten to the college years. Standardized tests provide accurate and quick ways to assess a student's working memory performance in order to best support their learning. A combination of strategies and training can improve the working memory capacity in our students, thus providing them with an opportunity to reach their potential.

\section{Endnote}

1 Throughout the article the reference to IQ scores is restricted to the Verbal or Performance subscales, rather than the Full Scale IQ score, which does include working memory tests in many of the standardised test batteries (e.g., Wechsler, Woodcock-Johnson, Stanford-Binet).

\section{References}

Alloway, T.P. (2007). Automated Working Memory Assessment. London: Pearson Assessment. Alloway, T.P. (2010). Improving working memory: Supporting students' learning. London: Sage.

Alloway, T.P. (2012a). Can interactive working memory training improving learning? Journal of Interactive Learning Research, 23, 1-11.

Alloway, T.P. (2012b). Automated Working Memory Assessment-2. London: Pearson Assessment. 
Alloway, T.P., \& Alloway, R.G. (2010). Investigating the predictive roles of working memory and IQ in academic attainment. Journal of Experimental Child Psychology, 106, 20-29.

Alloway, T.P., Alloway, R.G., \& Wootan, S. (2013). Home sweet home: Does where you live matter to working memory and other cognitive skills? Manuscript submitted for publication.

Alloway, T.P., Gathercole, S.E., Willis, C., \& Adams, A.M. (2004). A structural analysis of working memory and related cognitive skills in early childhood. Journal of Experimental Child Psychology, 87, 85-106.

Alloway, T.P., Bibile, V., \& Lau, G. (2013). Computerized working memory training: Can it lead to gains in cognitive skills in students? Computers \& Human Behavior, 29, 632-638

Alloway, T.P., Doherty-Sneddon, G., \& Forbes, L. (2012). Teachers' perceptions of classroom behavior and working memory. Education Research \& Reviews, 7, 138-142.

Alloway, T.P., Elliott, J., \& Place, M. (2010). Investigating the relationship between attention and working memory in clinical and community samples. Child Neuropsychology, 16, 242-254.

Alloway, T.P., Gathercole, S.E., \& Elliott, J. (2010). Examining the link between working memory behavior and academic attainment in children with ADHD. Developmental Medicine \& Child Neurology, 52, 632-636.

Alloway, T.P., Gathercole, S.E., Adams, A.M., Willis, C., Eaglen, R., \& Lamont, E. (2005). Working memory and other cognitive skills as predictors of progress towards early learning goals at school entry. British Journal of Developmental Psychology, 23, 417-426.

Alloway, T.P., Gathercole, S.E, Kirkwood, H.J., \& Elliott, J.E. (2008). Evaluating the validity of the Automated Working Memory Assessment. Educational Psychology, 7, 725-734.

Alloway, T.P., Gathercole, S.E, Kirkwood, H.J., \& Elliott, J.E. (2009). The cognitive and behavioural characteristics of children with low working memory. Child Development, 80, 606-621.

Alloway, T.P., Gathercole, S.E., \& Pickering, S.J. (2006). Verbal and visuo-spatial short-term and working memory in children: Are they separable? Child Development, 77, 1698-1716.

Alloway, T.P., \& Gregory, D. (2013). The predictive ability of IQ and working memory scores in literacy in an adult population. International Journal of Educational Research, 57, 51-56.

Alloway, T.P., \& Passolunghi, M.C. (2011). The relations between working memory and arithmetical abilities: A comparison between Italian and British children. Learning and Individual Differences, 21, 133-137.

Bull, R., \& Scerif, G. (2001). Executive functioning as a predictor of children's mathematics ability. Shifting, inhibition and working memory. Developmental Neuropsychology, 19, 273-293.

Buschkuehl, M., Jaeggi, S., \& Jonides, J. (2012). Neuronal effects following working memory training. Developmental Cognitive Neuroscience, 25, S167-S179.

Cain, K., Oakhill, J., \& Bryant, P. (2004). Children's reading comprehension ability: concurrent prediction by working memory, verbal ability and component skills. Journal of Educational Psychology, 96, 31-42.

Cowan, N. (2006). Within fluid cognition: Fluid processing and fluid storage? Behavioral and Brain Sciences, 29, 129-130.

Cowan, N., \& Alloway, T.P. (2008). The development of working memory in childhood. In M. Courage \& N. Cowan (Eds)., Development of memory in infancy and childhood (2nd ed., pp. 303-342). Hove, England: Psychology Press.

D'Amico, A., \& Guarnera, M. (2005). Exploring working memory in children with low arithmetical achievement, Learning and Individual Differences, 15, 189-202.

De Jong, P.F. (1998). Working memory deficits of reading disabled children. Journal of Experimental Child Psychology, 70, 75-96.

Engel, P.M.J., Heloisa Dos Santos, F., \& Gathercole, S.E. (2008). Are working memory measures free of socio-economic influence? Journal of Speech, Language, and Hearing Research, 51, 1580-1587.

Engle, R.W., Tuholski, S.W., Laughlin, J.E., \& Conway, A.R.A. (1999b). Working memory, short-term memory, and general fluid intelligence: A latent variable approach. Journal of Experimental Psychology: General, 125, 309-331.

Evans, G., \& Schamberg, M. (2009). Childhood poverty, chronic stress, and adult working memory. Proceedings of the National Academy of Sciences of the USA, 106, 6545-6549. 
Farah, M.J., Shera, D.M., Savage, J.H., Betancourt, L., Giannetta, J.M., Brodsky, N.L., Malmud, E.K. \& Hurt, H. (2006). Childhood poverty: Specific associations with neurocognitive development. Brain Research, 1110, 166-174.

Gathercole, S.E., Alloway, T.P., Willis, C., \& Adams, A.M. (2006). Working memory in children with reading disabilities. Journal of Experimental Child Psychology, 93, 265-281.

Geary, D. C. (1990). A componential analysis of an early learning deficit in mathematics. Journal of Experimental Child Psychology, 49, 363-383.

Geary, D.C., Hoard, M.K., \& Hamson, C.O. (1999). Numerical and arithmetical cognition: Patterns of functions and deficits in children at risk for a mathematical disability. Journal of Experimental Child Psychology, 74, 213-239.

Gersten, R., Jordan, N.C., \& Flojo, J.R. (2005). Early identification and interventions for students with mathematics difficulties. Journal of Learning Disabilities, 38, 293-304.

Heathcote, D. (1994). The role of visuospatial working memory in the mental addition of multi-digit addends. Current Psychology of Cognition, 13, 207-245.

Jaeggi, S.M., Buschkuehl, M., Jonides, J., \& Shah, P. (2011). Short- and long-term benefits of cognitive training. Proceedings of the National Academy of Sciences of the USA, 108, 10081-10086.

Kaplan, G. A., Turrell, G., Lynch, J. W., Everson, S. A., Helkela, E., \& Salonen, J.T. (2001). Childhood socioeconomic position and cognitive position in adulthood. International Journal of Epidemiology, $30,256-263$.

Leseman, P., Scheele, A., Mayo, A., \& Messer, M. (2007). Home literacy as a special language environment to prepare children for school. Zeitschrift für Erziehungswissenschaft, 10, 334-355.

Logie, R.H., Gilhooly, K.J., \& Wynn, V. (1994). Counting on working memory in arithmetic problem solving. Memory \& Cognition, 22, 395-410.

McGrew, K.S. (2009). CHC theory and the human cognitive abilities project: Standing on the shoulders of giants of psychometric intelligence research. Intelligence, 37, 1-10.

McLean, J.F., \& Hitch, G.H. (1999). Working memory impairments in children with specific mathematics learning difficulties. Journal of Experimental Child Psychology, 74, 240-260.

Messer, M.H., Leseman, P.P.M., Mayo, A.Y., \& Boom, J. (2010). Long-term phonotactic knowledge supports verbal short-term memory in young native and second language learners. Journal of Experimental Child Psychology, 105, 306-323.

Morrison, A.B., \& Chein, J.M. (2011). Does working memory training work? The promise and challenges of enhancing cognition by training work-ing memory. Psychonomic Bulletin \& Review, 18, 46-60.

Nation, K., Adams, J.W., Bowyer-Crane, C.A., \& Snowling, M.J. (1999). Journal of Experimental Child Psychology, 73, 139-158.

Noble, K.G., McCandliss, B.D., \& Farah, M.J. (2007). Socioeconomic gradients predict individual differences in neurocognitive abilities. Developmental Science, 10, 464-480.

Noble, K.G., Norman, M.F., \& Farah, M.J. (2005). Neuro-cognitive correlates of socioeconomic status in kindergarten children. Developmental Science, 8, 74-87.

Rasmussen, C., \& Bisanz, J. (2005). Representation and working memory in early arithmetic. Journal of Experimental Child Psychology, 91, 137-157.

Reuhkala, M. (2001). Mathematical skills in ninth-graders: Relationship with visuospatial abilities and working memory. Educational Psychology, 21, 387-399.

Siegel, L.S. (1988). Evidence that IQ scores are irrelevant to the definition and analysis of reading-disability. Canadian Journal of Psychology, 42, 201-215.

Siegel, L.S., \& Ryan, E.B. (1989). The development of working memory in normally achieving and subtypes of learning disabled children. Child Development, 60, 973-980.

Stothard, S.E., \& Hulme, C. (1992). Reading comprehension difficulties in children. Reading and Writing: An Interdisciplinary Journal, 4, 245-256.

Swanson, H.L., \& Beebe-Frankenberger, M. (2004). The relationship between working memory and mathematical problem solving in children at risk and not at risk for math disabilities. Journal of Education Psychology, 96, 471-491. 
Swanson, H.L., \& Sachse-Lee, C. (2001). Mathematical problem solving and working memory in children with learning disabilities: Both executive and phonological processes are important. Journal of Experimental Child Psychology, 79, 294-321.

Swanson, H.L., \& Saez, L. (2003). Memory difficulties in children and adults with learning disabilities. In H.L. Swanson, S. Graham, \& K.R. Harris (Eds.), Handbook of learning disabilities (pp. 182-198). New York: Guildford Press.

Thevenot, C., \& Oakhill, J. (2005). The strategic use of alternative representations in arithmetic word problem solving. Quarterly Journal of Experimental Psychology, 58A, 1311-1323.

Wagner, R.K., Torgesen, J.K., Rashotte, C.A., Hecht, S.A., Barker, T.A., Burgess, S.R., Donahue, J., \& Garon, T. (1997). Changing relations between phonological processing abilities and word-level reading as children develop from beginning to skilled readers: A 5-year longitudinal study. Developmental Psychology, 33, 468-479. 